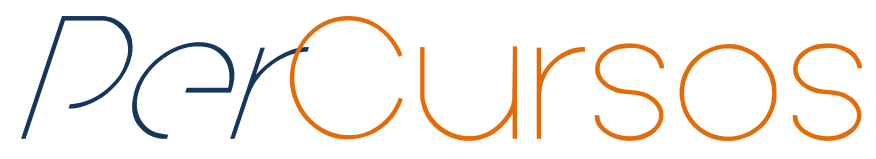

\title{
Mangal e Mucambo: diálogos de memórias e identidades entre comunidades tradicionais
}

\section{Resumo}

Os quilombos e as comunidades de fundo de pasto são denominados comunidades tradicionais porque, dentre outras peculiaridades, se utilizam de elementos de sua tradição cultural ancestral para produzir e reproduzir a existência no lugar onde vivem. Nesse contexto, a terra sempre foi elemento fundante na construção da identidade e na reprodução da vida dessas comunidades. O quilombo de Mangal e Barro Vermelho e a comunidade de Mucambo - objetos de análise neste texto - vivenciaram um processo sofrido de luta pela (re)conquista da terra ancestral visto que, embora fincados nela por longo tempo, quase foram usurpados por fazendeiros ou empresas interessadas nessas terras em razão do seu valor econômico. Neste trabalho, apresentamos os diálogos de memórias entre essas duas comunidades, situadas em diferentes regiões do estado da Bahia, no Brasil, demonstrando as intersecções entre as respectivas histórias, reveladoras de uma memória coletiva que atravessa tempos e espacialidades. Os dados que sustentam as discussões que aqui apresentamos são oriundos de uma dissertação de mestrado (2006) e de uma tese de doutorado (2013) que se utilizaram da história oral como metodologia e da entrevista como técnica de coleta de dados.

Palavras-chave: Quilombos -Bahia. Posse da Terra. Propriedade Territorial.

\section{Sandra Nivia Soares de Oliveira}

Doutora em Educação pela

Universidade Federal da Bahia

Professora Adjunta da

Universidade Estadual de Feira

de Santana - UEFS. Brasil

sandraniviasoares@gmail.com

\section{Izabel Dantes de Menezes}

Doutora em Educação pela

Universidade Federal da Bahia

Professora Adjunta da

Universidade do Estado da Bahia - UNEB. Brasil

bebeldm@yahoo.com.br

\section{Para citar este artigo:}

DE OLIVEIRA, Sandra Nivia Soares; DE MENEZES, Izabel Dantes. Mangal e Mucambo: diálogos de memórias e identidades entre comunidades tradicionais. Revista PerCursos, Florianópolis, v. 19, n.40, p. 221 - 241, maio/ago. 2018.

\section{DOI: 10.5965/1984724619402018221}

http://dx.doi.org/10.5965/1984724619402018221 


\title{
Mangal and Mucambo: dialogues of memories and identity between traditional communities
}

\begin{abstract}
The quilombos and the grassland communities are called traditional communities because, among other peculiarities, they use elements of their cultural ancestral tradition to produce and reproduce their existence in the place they live. On this context, the land has always been a founder element in the construction of the identity and in the reproduction of this communities' life. The quilombo of Mangal and Barrovermelho and the community of Mucambo objects of analysis in this text — have lived a suffering process of fighting to regain the ancestral land, because, in spite of being fixed to for a long time, they have been almost usurped by farms or companies that have interest in them because of their economic value. In this work we will present the dialogues of memories between these two communities, that are situated in different regions of Bahia, Brazil, demonstrating the intersections in these revealing communities' stories of a collective memory that passes through times and spaces. The data that sustain the discussions wich we present here are from a dissertation of a master (2006) and doctorate degree thesis (2013) that used the oral history as a methodology and the interview as a technique of data collect.
\end{abstract}

Keywords: Quilombos-Bahia. Possession of land. Territorial Property 


\section{Introdução}

Mesmo situadas em regiões extremas do estado da Bahia, as comunidades de Mangal/Barro Vermelho - localizada no município de Sítio do Mato, no Oeste da Bahia - e Mucambo - situada no centro-norte do estado - apresentam muitas aproximações identitárias que vão desde o mito fundador da comunidade até as estratégias de luta para fazer frente ao poder local. Para a escrita desse trabalho, foram tomadas, como referências, a dissertação de mestrado intitulada De Mangazeiros a Quilombolas: Terra, educação e identidade em Mangal e Barro Vermelho, defendida na Universidade do Estado da Bahia (OLIVEIRA, 2006), e a tese de doutorado Ecologias das identificações e suas sabenças na comunidade de fecho de pasto Mucambo, Antônio Gonçalves-BA, defendida na Universidade Federal da Bahia (MENEZES, 2012). Os trabalhos citados fizeram uso da etnografiacomo inspiração para a realização de suas pesquisas, e da História Oral como metodologia para conhecer as histórias e memórias das comunidades e os conflitos pela terra, utilizando as entrevistas para acessar as relíquias guardadas na memória dos moradores. Segundo Oliveira (2005,p. 97)),

Os registros traduzidos na oralidade pelo trabalho da memória trazem à tona os processos formativos significativos e as aprendizagens neles construídas, bem como os movimentos identificatórios - as identidades transformadas pelas experiências vividas em tempos/espaços como pessoa e profissional.

Valendo-se exclusivamente dos dados das pesquisas citadas, este trabalho analisa as aproximações entre essas comunidades no modo de luta pela conquista da terra, demonstrando a importância da terra ancestral na constituição e sobrevivência dessas comunidades negras que, mesmo em territórios de identidades diferentes e distantes na geografia do estado da Bahia, demonstram como o conflito agrário intercambia suas estratégias de dominação e como comunidades negras que nunca se comunicaram, uma vez que não são próximas geograficamente e nunca tiveram contato com a outra,reproduzem modos de se relacionar com o território que construíram e onde constroem a si mesmas, valendo-se da memória coletiva, da tradição e da solidariedade. 
Embora, inevitavelmente, esse texto aborde o conflito agrário, seufoco principal éevidenciar as intersecções no modo como essas comunidades viveram e construíram estratégias de lutas a fim de resistirem e se manterem em seu território ancestral. Ousaríamos dizer que buscamos demonstrar os diálogos de memórias realizados entre essas comunidades que desafiaram tempo e espaço, diálogos esses que se tornaram imprescindíveis no enfrentamento do conflito agrário que foi também uma luta pela sobrevivência das comunidades em sua materialidade e simbologia.

No Brasil, o tema das Comunidades Tradicionais é significativamente abordado, tanto no campo das formulações acadêmicas, desenvolvidas especialmente na área das Ciências Humanas, quanto nas esferas política e administrativa. A partir da década de 1980, discursos, pesquisas e dispositivos político-administrativos dos Governos Federal, Estadual e Municipal passam a incorporar, em seus expedientes, leis, decretos e políticas às "novas" categorias que nomeiam povos e comunidades tradicionais. As formulações teóricas ${ }^{1}$ a respeito dessa trajetória apontam que essa incorporação foi o resultado da luta pelo reconhecimento dos direitos territoriais, étnicos e culturais de comunidades historicamente "invisíveis". A condição de invisibilidade passa pela imposição de um modelo hegemônico que pretende tornar invisível tudo aquilo que não lhe é próprio subsumindo formas de vida, relações com o meio ambiente de maneira que pareçam anedóticos a fim de que a sua experiência não venha a ser compartilhada, sequer percebida como alternativa; ao contrário, os seus fazeres e saberes são empecilhos para o "progresso".

A emergência das identidades étnicas, na contemporaneidade, não ocorreu com exclusividade no estado da Bahia. De acordo com Almeida (2008, p. 19), em todo o país emergiram "novos padrões de relação política no campo". Estes novos padrões incorporam, segundo o Almeida (2008, p. 25),

[...] fatores étnicos, elementos da consciência ecológica e critérios de gênero e autodefinição coletiva, que concorrem para relativizar as divisões políticoadministrativas e a maneira convencional de pautar e de encaminhar demandas aos poderes públicos.

\footnotetext{
${ }^{1}$ Alcântara \&Germani (2010); Arruti (2006); Ferraro Jr. (2008a); Almeida (2008); Duprat (2007).
} 
Há, no entanto, na Bahia, uma concentração significativa de povos e comunidades tradicionais; isso garante diversidade de categorias².

\section{Comunidades de fundo e fecho de pasto}

A categoria de Fundo e Fecho de Pasto (FFP) foi criada em 1982 para nomear comunidades do semiárido baiano ${ }^{3}$ que fazem uso comum de terras. A origem dessas comunidades está relacionada à instalação e ao declínio do sistema sesmarial iniciado, ainda no período colonial, com as Capitanias Hereditárias em 1530 (FERRARO JR., 2008). Em meio ao abandono parcial das fazendas das Casas da Torre e da Ponte, a partir do século XVIII, as terras consideradas devolutas ${ }^{4}$ foram ocupadas por famílias que mantiveram um modo de vida intrinsecamente relacionado ao uso comunal de apossamentos, mais conhecidos como "fundo de pasto".

O projeto de colonização posto em prática no Brasil por três séculos suscitou, por meio de seus dispositivos jurídicos (a exemplo da Lei Imperial de Terras, 601/1850), um modelo de domínio da terra baseado na exploração dos recursos naturais e na concentração de grandes propriedades agrárias, “(...) produzindo conflitos pela posse e propriedade da terra ao longo de toda a história, inclusive na história contemporânea (TORRES, 2013, p. 29) ${ }^{6}$. No sertão baiano, o modo de vida baseado no uso comunal da

\footnotetext{
2 BAHIA, Decreto $n^{\circ}$ 13.247, dezo de agosto de 2011. Dispõe sobre a Comissão Estadual para a Sustentabilidade dos Povos e Comunidades Tradicionais - CESPCT. Diário Oficial Bahia, 30 ago. 2011. Disponível em:<http://www.legislabahia.ba.gov.br/index.php >. Acesso em: 13. 04. 2018.

3 Segundo Alcântara \&Germani (2005), o número oficial documentado pela Coordenação de Desenvolvimento Agrário (CDA) não inclui áreas de FFP não documentadas, no entanto, existem em quase todo o estado muitas comunidades que utilizam a terra de forma comunal. De acordo com a CDA, são 340 FFP distribuídos em 23 municípios baianos. De acordo com Ferraro Jr. (2008), o maior número de comunidades pertence aos municípios de Uauá e Monte Santo, cada município possui mais de 25 comunidades.

4 Como exigência legal, as terras "sem ocupação", nem cultivo eram devolvidas à Coroa Portuguesa e, depois do Império brasileiro, regulamentadas como devolutas pela lei Imperial de 1850.

${ }^{5}$ FERRARO JR. (2008), Alcântara \& Germani (2005) e Torres (2013).

${ }^{6}$ Ao se referir à situação fundiária de várias décadas do século XX, Torres (2013) utiliza uma análise de Pinto Ferreira (apud. TORRES, 2013, p. 37), na qual o mesmo afirmou que "o Brasil é o país do latifúndio. Foi e é. O
} 
terra se manteve devido ao relativo isolamento geográfico associado ao desinteresse econômico pela região (FERRARO, 2008). Contudo, de acordo com as narrativas dos moradores, a partir dos anos 1970, os conflitos na região se intensificam.

O mercado imobiliário passa a se interessar pelas terras de uso comum, atrelando a elas notoriedade econômica, política e social, atraindo especuladores e gerando, consequentemente, ameaças à manutenção do acesso e ao uso comum da terra por parte das comunidades, originando, sobretudo, conflitos. Os sujeitos atingidos por essas ameaças se agruparam em torno dessa "identidade coletiva" - Fundo e Fecho de Pasto e encaminharam ao Estado suas demandas por reconhecimento legal (ALMEIDA, 2008).

Nesse sentido, a adesão de comunidades que fazem uso comum da terra à categoria está diretamente relacionada aos conflitos envolvendo camponeses e fazendeiros grileiros da região, colocando, assim, a "questão agrária" como cerne dos conflitos e das lutas em defesa da terra (GERMANI, 2010). Para responder às ameaças, por vezes violentas, vindas dos grileiros e fazendeiros, essas comunidades se organizaram em torno da expressão que nomeia o sistema comunal de terra - fundo de pasto - e que se torna “[...] não apenas uma forma de viver no sertão, mas uma forma de organização e luta para viver no sertão" (CAVALCANTE, 2007, p. 113), transforma-se em uma categoria que nomeia, como apontado por Almeida (2008), uma identidade territorial coletiva.

A Articulação Estadual das Comunidades de Fundo e Fecho de Pasto sistematiza em seu documento "o fundo de pasto que queremos" (2003), as características do sistema Fundo de Pasto em destaque para a questão do uso comum da terra, os laços de compadrio e parentesco entre os membros, características culturais específicas e o cuidado com o bioma caatinga, a saber:

[...] posse, por décadas, de áreas coletivas usadas em pastoreio extensivo; livre utilização da área por todos os condôminos; ausência de delimitação com cercas;

residências típicas do sertão na área das posses individuais; 
roçados de subsistência individuais de cada família;

forte laço de parentesco e compadrio entre os membros da comunidade;

características culturais próprias de cada comunidade: festas, artesanatos, rezas, etc;

Cuidado com a caatinga. (ARTICULAÇÃO, 2003, p. 4-5) ${ }^{7}$

O conjunto de comunidades aglutinadas sob a "identidade territorial coletiva" de Fundo de Pasto é considerado por alguns autores, (FERRARO, 2008; ALCÂNTARA; GERMANI, 2005),como realidade plural de diferentes contextos socioculturais. As comunidades FFP não possuem, portanto, características idênticas; há uma diversidade, não apenas no que tange às questões climáticas, mas também na composição cultural, étnica e, sobretudo, nos processos de territorialização.

Assim, diante da diversidade de comunidades que compõem a categoria FFP, elegemos, como lócus, a comunidade de Fecho de Pasto Mucambo (BA), pois esta expressa vínculo estável com um "sistema de uso comum", denominado de Serra da Várzea Comprida, localizada ao norte da Bahia, e por ser pioneira na luta em defesa da Serra da Várzea Comprida.

\section{O Mucambo}

Mucambo é pequena aglomeração descontínua de casas, cercadas de roças familiares, com uma igreja situada no centro, uma escola, um campo de futebol, dois bares, uma casa de farinha, a Associação e, ao fundo, ou melhor, ao fecho ${ }^{9}$, grande área com 3.366 hectares de terra de uso comum. A área de Fecho situa-se entre serras de uma cordilheira, dona de nascentes e vales, e possui grande diversidade de fauna e flora. As narrativas sobre a procedência da comunidade circulam em torno do mito de origem centrado na figura mítica de uma índia chamada de Mucamba. O que nos faz refletir, ao ouvir os relatos dos entrevistados sobre a origem da comunidade, é que esse mito de

\footnotetext{
${ }^{7}$ Articulação Estadual de Fundos e Fechos de Pasto foi criada em 1974, e possui 400 associações agropastoris organizadas (ALMEIDA, 2008, p. 109).

${ }^{8}$ Expressão de Almeida (2008).

${ }^{9}$ A questão climática trouxe para a categoria Fundo de Pasto a necessidade de inclusão do termo Fecho para, dessa forma - Fundo e Fecho de Pasto -, acolher as comunidades localizadas "nos altos" com características climáticas, sociais e culturais distintas (ALCANTARA \& GERMANI, 2005). O Mucambo é um Fecho de Pasto.
} 
origem personalizado na mulher nos remete à ideia de fertilidade. Fertilidade que se traduz nas terras férteis dos vales que acolhem a comunidade de Mucambo, filha de Mucamba e irmã de todos que dela descendem.

Além disso, a indicação do nome próprio como base do mito sugere identificação étnica legítima haja vista a presença indígena no território brasileiro. Percebe-se, portanto, que o topônimo Mucambo é contrário à "apressada associação etimológica" a uma referência étnica africana ${ }^{10}$. Dessa maneira, o sinuoso e complexo caminho percorrido pela memória dos moradores da comunidade do Mucambo nos leva a nuances de um processo histórico em que esses sujeitos situam-se no mito, interligando o presente a uma temporalidade mítica e histórica. Essa dinâmica nos remete, segundo LÉVI-STRAUSS (1984),

[...] a um passado geral que vai constituir o primeiro domínio onde a memória coletiva cristaliza-se, associando a imaginação destes sertanejos à experiência fundadora. Como as narrações míticas, elas possuem valor de paradigma, constituindo assim modelo de referência que lhes permite situar no seio deste "conjunto camponês". Estas narrações, contudo, não se situam no domínio do mito, nem no da história, mas na intersecção de ambos. (apud GODOI, 1999, p. 110, grifo nosso)

De acordo com relatos orais dos moradores mais velhos da comunidade, a paz reinou até o início da década de 1970; a partir deste período, as Serras da Várzea Comprida e Várzea Redonda (áreas de terra comum) vão se constituir em palco de tentativas de conflitos de terras. Na base desses conflitos de 1970 estão três fatos datados ainda nas décadas de 1950 e 1960. Impulsionados pelas estratégias integracionistas dos governos republicanos - que a partir da década de $1950^{11}$ tentam constituir políticas de integração da região ao processo de desenvolvimento nacional -, fazendeiros, pecuaristas e mineradores passam a se interessar por estas terras até então

\footnotetext{
${ }^{10}$ No dicionário do século XVIII, a palavra Mucambo significa "habitação feita nos Mattos pelos escravos fugidos do Brasil" ou "habitação que fazem os pretos fugidos, chamada por outro nome, quilombo" (VIEIRA FILHO, 2006).

${ }^{11}$ De acordo com Germani (2010), "a política de incentivo fiscal desenvolvida pelo governo federal no Nordeste, representado pela Superintendência do Desenvolvimento do Nordeste (SUDENE) e pelo Departamento Nacional de Obras Contras as Secas (DNOCS), buscou desenvolver projetos que facilitassem a expansão do capital no campo com obras de infra-estrutura e financiamentos" (GERMANI, 2010, p. 46).
} 
consideradas não rentáveis, dando origem à prática de grilagem de terras na região. 0 segundo fato está relacionado ao início da exploração da esmeralda na Serra da Carnaíba por empresas mineradoras: a Ferros e Ligas da Bahia S/A FERBASA, desde 1962, e a CIMPOR, desde 1976 (CPT - cartilha, 2009); e por último, o cultivo de uma cultura ilícita, cannabis (maconha), nos vales das serras. De acordo com os relatos dos moradores, esses fatos provocaram impactos ambientais e sociais, a exemplo de desmatamentos e medo na população, respectivamente, assim como sanções e restrições ao uso da terra comum.

Os fatos ocorridos colocam em risco a reprodução física, cultural, social e econômica da vida das populações locais. A terra comum é onde se produz a vida na comunidade. A Serra do Refrigero, onde ela está fincada, significa o próprio nome dado: "refrigero" para o gado em tempos de seca, fonte de água potável com suas inúmeras nascentes, córregos e rios, ou seja, fonte de vida material imprescindível para a sobrevivência do grupo, é também palco e razão da organização política, mas significa também fonte de vida imaterial que guarda, na área do segredo, água milagrosa que cura $^{12}$.

Os empreendimentos, além de alterar a aparência da paisagem das serras, modificaram as relações entre as pessoas, ao impor restrições no uso de determinada área, e condicionaram o medo, comprometendo a vida do e no lugar em sua inteireza.

Diante do contexto, os moradores se organizam e invocam a defesa da área comum. O reconhecimento legal acontece em 1989.Com a realização desta pesquisa foi possível identificar o reconhecimento legal do arranjo costumeiro de uso e ocupação da terra; isso foi possível porque a comunidade, diante do conflito, acionou saberes tramados no seio das relações entre família, trabalho e religião.

\footnotetext{
${ }^{12}$ Uma caverna conhecida apenas por algumas pessoas da comunidade, daí o nome "área do segredo", de onde mina uma água milagrosa.
} 


\section{Quilombo}

Tradicionalmente, quilombo designa esconderijo de negro fugido. De acordo com o parágrafo terceiro do regimento de 1724 , por quilombo se devia entender "[...] toda habitação de negros fugidos que passe de cinco em parte despovoada ainda que não tenham ranchos levantados nem nela se achem pilões" (LARA, 1996, p.96). O regimento de 1733, aprovado pela Câmara de São Paulo, apresenta outra definição de quilombo, sendo este "[...] o ajuntamento de mais de quatro escravos vindos em matos para viver neles e fazerem roubos e homicídios [...]" (LARA, 1996, p.97). Outra definição é apresentada, em 1757, pela Câmara de São Salvador dos Campos dos Goytacases que, ao se referir a quilombo, o definia como:

[...] Escravos que estivessem arranchados e fortificados com ânimo a defender-se [para] que não sejam apanhados, esclarecendo que os tais ranchos não eram quaisquer, mas daqueles em que ficam "por se repararem do tempo" e estipulavam que "achando-se de seis escravos para cima que estejam juntos se entenderá também [por] quilombo." (LARA, 1996, p. 97, grifo da autora)

Observa-se que, no contexto da escravidão, o conceito de quilombo variou de acordo, certamente, com a realidade de cada lugar. Sublinhando a questão limítrofe do número de escravos, o ponto de intersecção está na fuga do regime, indicando o movimento que fez o conceito para se adequar às realidades e experiências naquele contexto, "tratando-se de uma definição operacional diretamente ligada ao estabelecimento dos salários do capitão-do-mato, mas que é, sobretudo, uma definição política" (LARA, 1996, p.97).

A Constituição Federal de 1988, em seu artigo 68, dos Atos das Disposições Constitucionais Transitórias, reconhece, aos remanescentes das comunidades dos quilombos que estejam ocupando suas terras, a propriedade definitiva destas, tendo o Estado a obrigação de Ihes emitir os títulos (BRASIL, 1988). Consequentemente, está posta a necessidade de repensar o conceito de quilombo a partir da diversidade de 
comunidades negras. Como afirma Oliveira, S., utilizando-se das palavras de Santo Silva (1997),

A questão agora era definir o que se compreende por quilombo neste momento, para poder reconhecer seus remanescentes. Mais uma vez, será no campo da política que o sentido/conceito de quilombo será redefinido. (OLIVEIRA, 2006, p.84)

Com essa preocupação, em 1994, surgiu um grupo de trabalho dentro da Associação Brasileira de Antropologia (ABA), apresentando, como objetivo principal, construir uma definição para as terras pertencentes a comunidades negras consideradas remanescentes de quilombos. O documento produzido por este grupo de trabalho quilombo, é assim definido:

Contemporaneamente, portanto, o termo quilombo não se refere a resíduos ou resquícios arqueológicos de ocupação temporal ou de comprovação biológica. Também não se trata de grupos isolados ou de uma população estritamente homogênea. Da mesma forma nem sempre foram constituídos a partir de movimentos insurrecionais ou rebelados, mas, sobretudo, consistem em grupos que desenvolveram práticas cotidianas de resistência na manutenção e reprodução de seus modos de vida característicos na consolidação de um território próprio. (O’DWYER, 1995 apud MOURA, G., 1999, p.102-103)

Como resultado da luta do Movimento Negro, a partir da promulgação da constituição de 1988, quilombo, uma categoria coletiva (VÉRAN, 1998, p.199) que estava no passado, é retomada, e seu conceito ganha novo sentido. O conceito de quilombo é, nesse momento, reconstruído politicamente no jogo do poder, abrindo possibilidades para as populações negras rurais do direito ao reconhecimento de uma ancestralidade que lhes garantirá benefícios políticos e materiais.

Abordar a ressemantização do conceito de quilombo é importanteporque só a partir daí é possível pensar em Mangal como quilombo, visto que as comunidades negras de Mangal e Barro Vermelho não aparecem na narrativa de seus moradores, nem emqualquer outro documento, como tendo sidoum quilombo nos moldes apresentados 
pela historiografia tradicional - como lugar de negro fugido. Mangal e Barro Vermelho têm todas as características daquilo que podemos denominar de Terra de Santo, como evidencia o depoimento do senhor Isauro Lobo (2005), quando interrogado sobre a origem da terra: “[...] a terra pra Santa, quem deu foi uma mulher que tinha aqui que era de minha família [...]."

Diante desse cenário, no estudo dessa comunidade, a memória a ser valorizada não é se o grupo em questão tem ou não alguma relação com as formações que se encaixam na definição tradicional de quilombos, que tem em Palmares sua principal referência; outros elementos precisam ser considerados, especialmente se pensarmos em quilombo como uma categoria que se justifica para além da definição de um espaço físico, se justifica como um modo de se portar no mundo diante da experiência da escravidão e da discriminação. Quilombo, nessa perspectiva, é o lugar da resistência, e resistência não se dá de uma mesma forma em territórios e contextos diferentes, muito menos entre sujeitos diferentes. Não reconhecer essa complexidade é desconsiderar a dialética das relações entre os sujeitos e seus contextos e entre si.

Fora dessa perspectiva, Mangal jamais poderia ser reconhecido como quilombo, pois mesmo o termo quilombola era desconhecido na Comunidade, como podemos observar na fala de um dos moradores: "[...] o senhor desculpa as minhas expressão, a minha ingnorança, o que... que é quilombo? Porque o quilombo que, que... que eu entendo é quilometrage, é midição". A fala de Senhorzinho, diante do representante do Instituto Nacional de Colonização e Reforma Agrária (INCRA) em 1997, e ratificada em depoimento em 2005, deixa claro que nem sempre se foi quilombola em Mangal/Barro Vermelho e, portanto, Mangal nem sempre foi quilombo, considerando a concepção tradicional.

\section{A comunidade de Mangal e Barro Vermelho}

Em Mangal é assim: não existe uma única família que não esteja ligada à outra. Lá todo mundo é parente. Nesse sentido, o senhor Isauro afirma, orgulhosamente 
[...] Aqui só tem uma famia sozinha. É que agora foi que misturou muito que os mais novo quando casou, já casou com moça do outro lado, outros casou pra Paratinga e misturou. Nós aqui era uma famia só. (2005, $\mathrm{s} / \mathrm{p})$

Dona Pituca (2005), na tentativa de explicar o quão são imbricadas as relações de parentesco que os unem, dispara: “[...] Aqui o pau que dá ni Chico também dá ni Francisco". Os laços de parentesco e os núcleos familiares fortes, a partir dos quais se originou a comunidade, são elementos importantes nas relações de comunidades negras rurais. Em especial, na Comunidade de Mangal, esses dados foramfundamentais no reconhecimento dessa comunidade como remanescente de quilombo, pois o laudo antropológico,

constitui-se por referência a dois elementos fundamentais, parentesco e território. Estas são, por assim dizer, as dimensões objetivas deste fazerse da comunidade de Mangal [que], através da rede de parentesco e do território como base material, encontra expressão. (MESSEDER; NASCIMENTO, 1998, p. 8)

O povo do Mangal está arraigado naquelas terras, segundo a tradição oral, às margens do Rio São Francisco - no Município de Sítio do Mato no Oeste do estado da Bahia - desde o século XVIII, onde construíram a experiência histórica de se reproduzirem, de produzirem as condições de sua existência e de reproduzirem a cultura de seus ancestrais, nem sempre do mesmo jeito, mas no jogo da vivência e sobrevivência, conservando e/ou reformulando significados.

Segundo os relatos orais, a comunidade surge a partir da escravaria de certo Capitão João que teria se apaixonado por uma escrava e que, a pedido dela, teria doado a terra a Nossa Senhora do Rosário. Desde então, os negros da fazenda passaram a morar no Mangal, lugar onde se soltava o gado. Na negociação com seu entorno, durante muito tempo, a comunidade - de origem escrava e adepta a práticas religiosas de matriz africana -, negou sua crença, tomando a Nossa Senhora do Rosário como padroeira. Ser Mangazeiro era ser reconhecido pelo entorno como negros feiticeiros. 
O modo como Mangal garantiu a sobrevivência dos elementos, destacados por eles como fundantes na construção da identidade, tem como cenário um pedaço de terra às margens do Rio São Francisco, que é o lugar onde se desenvolveram mitos, ritos, fazeres e saberes que, para eles, dão suporte à identidade do grupo ou à identidade de cada um, faz dele quilombo, compreendido como lugar de resistência e de transgressão.

Mangal reivindicou a identidade quilombola no bojo da luta pela terra, a qual, posteriormente, se desdobrou num processo de retomada de sua história e identidade. Foi assim que a comunidade em pouco mais de dois anos passou de mangazeira a quilombola ao ser reconhecida como "remanescente" de quilombo em 1998, inclusive pelo reconhecimento de que não se tornariam quilombolas se não fossem mangazeiros ${ }^{13}$.

\section{Diálogos de memória entre Mangal e Mucambo}

As relações entre as comunidades citadas serão analisadas a partir de três aproximações: o mito fundador, as relações de parentesco e a luta pela terra. Outras relações poderiam ser estabelecidas visto que há uma fartura de experiências que aproximam culturalmente as comunidades aqui estudadas; entretanto, pelos limites desse trabalho, nos deteremos nos elementos citados.

Embora situadas geograficamente distantes, as comunidades de Mangal e Mucambo estão ligadas historicamente, a começar por seus mitos fundadores. Em Mucambo, a Índia Mucamba, uma mulher, é o “princípio" da origem ancestral da memória e da identidade do grupo marcando o lugar e as relações. Em Mangal, Deltrudes, também uma mulher, demarca o espaço - três léguas de terra que não por acaso também são doadas a uma divindade feminina, Nossa Senhora do Rosário. As mulheres sinalizam a origem material e simbólica nessas comunidades. Além disso, mesmo Mucamba sendo uma índia, referência étnico-racial da comunidade de Mucambo, a palavra mucambo está diretamente ligada às formações dos quilombos, que dentro do período escravista, constituiu-se como

\footnotetext{
${ }^{13}$ Mangazeiros era a forma pejorativa como os moradores do entorno identificavam a comunidade.
} 
Movimento de rebeldia permanente organizado e dirigido pelos próprios escravos que se verificou durante o escravismo brasileiro durante todo o território Nacional. Movimento de mudança social provocado, ele foi uma força de desgaste significativa ao sistema escravista, solapou as suas bases em diversos níveis - econômico, social e militar - e influi poderosamente para que esse tipo de trabalho entrasse em crise e fosse substituído pelo trabalho livre. (MOURA, C.,1992, p. 23)

Dessa forma, na origem dessas comunidades está a relação com o passado escravo, embora essa memória não seja reivindicada pelos moradores do Mucambo. Numa heteroidentificação, ousamos afirmar que o Mucambo é uma comunidade negra e que a sua formação pode ter se dado na intersecção entre os povos indígenas e os negros escravizados.

Outra intersecção entre as comunidades é o lugar dos mais velhos, sustentáculos das famílias, guardiões da memória da comunidade; só a partir deles é possível a reconstrução da história dessas comunidades. Muitas memórias soterradas tiveram que ser "escavadas", expressadas, reelaboradas com o processo de conquista da terra, assim como também, sob este processo, se deu a construção da identidade de cada comunidade, partindo do princípio de que

Tanto a identidade pessoal quanto a identidade socialmente derivadasão formadas em diálogo aberto. Estas dependem de maneira vital das relações dialógicas estabelecidas com os outros. Esse é um movimento pelo qual passa todo e qualquer processo identitário. (GOMES, 2002, p.39)

As relações de parentesco demonstram semelhanças entre essas comunidades; essas relações são consideradas, pelos trabalhos que embasam este artigo, fatores primordiais na caracterização e na análise destas comunidades. Tanto Oliveira, S. (2006), quanto Menezes (2012), refletem sobre os campos de atuação das famílias dentro da comunidade como elementos de sustentação afetiva e, também, política porque são mediadas por conflitos e negociações de ordens particulares ou públicas, individuais ou 
coletivas que, ao longo da existência, foram produzindo as relações sociais na comunidade. Nesse contexto,

Cada família nuclear pode ser compreendida como pequenos núcleos que se relacionam e estão imbricados no sentido mais amplo ao território da grande família - a comunidade. "Todo o mundo", no sentido de toda a comunidade, é tecido por laços de parentesco onde cada família está imbricada na outra.(MENEZES, 2012, p. 93, grifo da autora).

Num e noutro caso, percebe-se o quanto estar juntos garantiu a existência tanto no plano material, quanto no de suas simbologias. Não seria absurdo afirmar que essas relações garantiram a sobrevivência da comunidade por conta de uma comunalidade familiar.

A terra é outro elemento fundante na história e na memória de Mangal e Mucambo. Com ela se mantém uma relação para além do espaço físico. É uma terra ancestral que conecta o passado e o presente. Essas comunidades se construíram em suas terras e por suas terras ao mesmo tempo em que construíam cada plantio e colheita, a cada manifestação cultural, a cada luta, cada labuta. Essas terras foram "feitas" por eles, e elas os fizeram. As tentativas de usurpação de sua terra/território se constituíram em estímulo para a construção/afirmação de suas identidades que não podem ser pensadas sem seus mitos e parentes. Essas relações imbricadas fazem as terras de Mangal e Mucambo particulares e plurais porque ao contarem suas histórias, elas contam as histórias de outras comunidades que se construíram na resistência e como resistência numa sociedade que, pela usura, não se furta de construir uma relação de morte com as comunidades tradicionais. Não apenas morte física, quando tentam tirar-lhes o lugar de sustento de produção do alimento, mas, também, morte cultural dessas comunidades, no sentido de sua relação simbólica com a terra. Sair de lá implica em abandonar suas memórias, sua ancestralidade, seus mortos, pois a terra para essas comunidades configura-se como, 
território para além de espaço físico, é também espaço político no qual são implementadas ações e negociações que possibilitam ao grupo a manutenção de valores comunitários que, certamente, garantiram a sobrevivência do grupo em meio a todos os conflitos vividos. Nesse contexto, "o território aparece assim como um dado necessário à formação da identidade grupal/individual, ao reconhecimento de si por outros". (SODRÉ, 1999 apud OLIVEIRA, S., 2006,p.93)

A luta das comunidades negras pela conquista da terra difere da luta de outros setores rurais, porque a terra que essas comunidades reivindicam traz consigo uma ancestralidade que a faz mais do que terra, fundindo-se com a própria história do indivíduo, quase uma extensão de seu corpo. Essas comunidades além de produzirem na terra, produzem a terra cotidianamente, tornando-a particular, única; uma terra que sempre foi de alguém, um conhecido, de quem foi herdada toda a referência de uma terra impregnada de uma historicidade que a particulariza.

Podemos dizer que no contexto do conflito agrário, os moradores do Mucambo e de Mangal e Barro Vermelho acionaram a trajetória, a memória, a origem étnica como fator de legitimação de suas bases territoriais fazendo a viagem de volta, atuando sincronicamente. Nessa circunstância,

[...] próprio das identidades étnicas é que nelas a atualização histórica não anula o sentimento de referência à origem, mas até mesmo o reforça. É da resolução simbólica e coletiva dessa contradição que decorre a força política e emocional da etnicidade. (OLIVEIRA, J., 2004, p. 32-33)

A resistência no conflito agrário, cujo objetivo principal era o de preservar o território, torna-se o estopim para outras conquistas. A mobilização da memória ancestral, a contação de suas histórias para os mais jovens são ganhos imateriais que ajudaram a construir e a ressignificar identidades. No plano político, o reconhecimento dessas áreas como comunidades tradicionais as coloca em uma posição de prestígio perante seu entorno. Economicamente, esse reconhecimento possibilitou-lhes acesso a políticas direcionadas a essas comunidades, garantindo-lhes melhor qualidade de vida. 


\section{Considerações finais}

Nas duas comunidades, a relação com a terra, a luta por ela, as relações de parentesco e os mitos fundadores se relacionam. São muitas as intersecções tanto de conteúdo quanto de método nessas relações; isso porque as comunidades estão unidas pelo passado, pela relação com a colonização, pela escravidão e pela marginalização dos povos indígenas e dos negros submetidos à violência histórica. Manter-se na terra, preservar suas memórias e o fortalecer dos laços de parentesco foram conteúdos e métodos de sobrevivência.

Assim, a afirmação de uma origem ancestral, como bem sinaliza Maffesoli (1997), move política e emotivamente a defesa da terra e, acreditamos, move um saber memória como resplendor da existência do grupo na base territorial. São histórias míticas que "servem de substratos ao estar-junto e ressurgem sempre que a necessidade se faz sentir" (MAFFESOLI, 1997, p. 145). Dessa maneira, a tradição oral sobre a origem das comunidades é posta em um documento escrito. No exercício de trazer à tona a memória do passado, Godoi (1999, p. 111) indica que "assiste-se ao caminhar da história em direção ao mito". Nesse caminho tortuoso para compreender a relação entre a história e o mito fundador, outras evocações surgem como marcas fundantes da vida do grupo, a exemplo da referência da Igreja, da religião de matriz africana, do mito fundador que nas comunidades são femininos - Deltrudes e Mucamba - e, também, em direção à nossa história através da memória da escravidão, dos povos indígenas e, ainda, na doação da solidariedade como condição para a sobrevivência, da afirmação dos laços de parentesco como rede de proteção contra a opressão, a perda de suas histórias, garantindo a alimentação da memória. As relações entre as comunidades, aqui estudadas, estão imbricadas porque fazem parte do mesmo processo histórico que dá corpo à própria sociedade brasileira. 


\section{Referências}

ALCANTARA, Denilson Moreira de; GERMANI Guiomar Inez. Fundo de pasto: espaços comunais em terras baianas. ENCONTRO DE GEÓGRAFOS DA AMÉRICA LATINA, $X-20$ a 26 de março, 2005, São Paulo. Anais...São Paulo: Universidade de São Paulo, 2005. p. 336360.

ALCANTARA, Denilson Moreira de; GERMANI Guiomar Inez. As comunidades de Fundo e Fecho de Pasto na Bahia: luta na terra e suas espacializações. Revista de Geografia. Recife: UFPE/DCG/NAPA, v. 27, n. 1, p. 40-56, jan./abr., 2010.

ALMEIDA, Alfredo Wagner Berno. Terra tradicionalmente ocupadas: terras de quilombo, terras indígenas, babaçuais livres, castanhais do povo, faxinais e fundo de pasto. Manaus: PGSCA-UFAM, 2008.

\section{ARTICULAÇÃO ESTADUAL DOS FUNDOS E FECHOS DE PASTO. O fundo de pasto que} queremos. Salvador: 2003. Texto impresso.

ARRUTI, José Maurício. Mocambo: antropologia e história do processo de formação quilombola. Bauru, SP: EDUSC, 2006.

BAHIA, Decreto n ${ }^{\circ} 13.247$ d e30 de Agosto de 2011. Dispõe sobre a Comissão Estadual para a Sustentabilidade dos Povos e Comunidades Tradicionais - CESPCT. Diário Oficial Bahia, 30 ago. 2011. Disponível em:<http://www.legislabahia.ba.gov.br/index.php $\geq$. Acesso em 13. 04.2018

BRASIL. Constituição (1988) - Artigo 68:Das Disposições Nacionais Transitórias - do direito à terra e à titulação aos herdeiros da resistência ao regime de escravidão no Brasil, Brasília, DF:Senado.1988. Disponível em: <http://www2.camara.leg.br/atividade-

legislativa/legislacao/Constituicoes_Brasileiras/constituica01988>. Acesso em: 25 set. 2017.

CAVALCANTI, Ludimila Oliveira Holanda. A escola família agrícola no sertão: entre os percursos sociais, trajetórias pessoais e implicações ambientais. 2007. Tese (doutorado em Educação) - FACED-UFBA, 2007.

DUPRAT, Deborah. Pareceres jurídicos:direito dos povos e das comunidades tradicionais. Manus: PPGSCA-UFAM/ Fundação FordManaus: UEA, 2007. (Coleção documentos de bolso, n. 2)

FERRARO Jr., Luiz Antônio. Entre a invenção da tradição e a imaginação: estudo de caso dos fundos de pasto na Bahia, 2008. 459 f.Tese (Doutorado em Desenvolvimento Sustentável). Centro de Desenvolvimento sustentável, Universidade Federal de Brasília, Brasília, 2008. 
GERMANI, Guiomar Inez. Questão agrária e movimentos sociais: a territorialização da luta pela terra na Bahia. In: COELHO NETO, A. S.; SANTOS, E. M. C.; SILVA, O. A. (Orgs.). (GEO) grafias dos movimentos sociais. Feira de Santana (BA): UEFS Editora, 2010, v., p. 269-304.

GODOI, Emília Pietrafesa de. Trabalho da memória: cotidiano e história no sertão do Piauí. Campinas, SP: Editora Unicamp, 1999.

GOMES, Nilma Lino. Educação e identidade negra. UFMG: Aletria, 2002. Disponível em: $<$ http://www.letras.ufmg.br/poslit>. Acesso em: set. 2017.

LARA, Silvia Hunold. Do singular ao plural: Palmares, capitães-do-mato e o governo dos escravos. In: REIS; GOMES (Orgs.). Liberdade por um fio: história dos quilombos no Brasil. São Paulo: Companhia das Letras, 1996.

MAFFESOLI, M. O tempo das tribos. Rio de Janeiro, Forense-Universitária, 1997, 232 p. MENEZES, Izabel Dantas de. Ecologia das identificações e suas sabenças na Comunidade de Fecho de Pasto Mucambo, Antonio Gonçalves, Bahia. UFBA. 2012. 178 f. Tese (Doutorado em educação): -Universidade Federal da Bahia. Faculdade de educação, Salvador, 2012.

MESSEDER, Marco Luciano Lopes; NASCIMENTO, Marco Tromboni de S. Relatório de Identificação da Comunidade de Mangal -Estado Bahia. Brasília : Fundação Cultural Palmares:

MEC, 1998.

MOURA, Clóvis. História do negro brasileiro. São Paulo, Ática, 1992.

MOURA, Glória. Os quilombos contemporâneos e a educação. Revista Humanidades. UnB



OLIVEIRA, João Pacheco de (Org.). A viagem da volta: etnicidade, política e reelaboração cultural do nordeste indígena. Rio de Janeiro: Contra-Capa, 2004.

OLIVEIRA, Valeska Fortes de. Educação, memória e história de vida: usos da história oral.História Oral Revista da Associação Brasileira de História Oral, São Paulo, v. 8, n. 1, jan.-jun. 2005

OLIVEIRA, Sandra Nivia Soares. De mangazeiros a quilombolas: terra, educação e identidade em Mangal e Barro Vermelho Sítio do Mato-Bahia, 2006. 180f. Dissertação (Mestrado em Educação)- Universidade Estadual da Bahia, Departamento de Educação Campus I. Salvador, 2006.

TORRES, Paulo Rosa. Terra e territorialidade das áreas de fundos de pastos do semiárido baiano 1980-2010.Feira de Santana: UEFS Editora, 2013.

VÉRAN, Jean-François. Rio das Rãs: Memória de uma "Comunidade Remanescente dequilombo" Revista Afro-Àsia, n. 23.Salvador: CEAO/EDUFBA, 1998. 
VIEIRA FILHO, Raphael Rodrigues . Os negros em Jacobina (Bahia) no século XIX. 2006. 240f. Tese (Doutorado em história) - Pontifícia Universidade católica de são Paulo, PUC/SP., 2006. 